\title{
Public Procurement in the Presence of Capital Taxation
}

\author{
by \\ Alfons J. Weichenrieder \\ (CESifo Munich)
}

20. October 1999

\begin{abstract}
The paper considers governments' public procurement decision as a way of influencing industry structure. In a federation in which capital is mobile and capital taxation is harmonized, a home bias in public procurement can potentially be explained as an effort to increase the capital intensity of local production and to attract taxable capital. As a result, governments may prefer domestic firms to more efficient foreign firms. JEL classification: H57, H77
\end{abstract}

Keywords: procurement, tax competition, federalism.

Alfons J. Weichenrieder

CESifo Munich

Schackstr. 4

80539 Munich

Germany

Tel: ++49 89 2180-2089

Fax: ++4989397303

Email: a.weichenrieder@ces.vwl.uni-muenchen.de

\footnotetext{
${ }^{+}$I am indebted to Ronnie Schöb and Massimo Bordignon for helpful discussion and to an anonymous referee for important comments and detailed suggestions. All errors are mine.
} 


\section{Non-technical Summary}

Preferential treatment of local firms in procurement decisions is a frequent source of discontent. To answer the question of how to limit governments' local preferences in procurement it is crucial to understand what governments' motives are.

The present paper develops a model in which small jurisdictions prefer domestic firms to foreign firms even though the domestic firms charge a higher price for identical quality. The reason for this inefficient outcome is a fiscal externality among governments. If jurisdictions within a federation decide to tax mobile factors, then public procurement in capital intensive sectors can redistribute tax revenues between jurisdictions. More precisely, awarding public procurement contracts in capital intensive sectors to less efficient domestic firms boosts that sector and attracts mobile capital. Since capital is taxed, one jurisdiction's tax revenue is increased at other jurisdictions' expense.

For jurisdictions with firms that are competitive on foreign markets it is somewhat more difficult to boost the domestic procurement sector since domestic purchases may simply crowed out exports. The model implies that, while efficient jurisdictions have no home bias, they may nevertheless buy too much of the procurement good to attract capital.

The identified mechanism of attracting a tax base by strategic procurement decisions makes clear that tax competition may continue even after tax rates have been harmonized. 


\section{Introduction}

Preferential treatment of local firms in procurement decisions is a frequent source of discontent. In the EU, e.g., one of the main objectives of the Europe-1992 program was to reduce those local preferences and to increase the fraction of procurement contracts awarded to firms from other member states. Preferences for local firms are also at work in the US. For decades, the US 'Buy American Act' has forced foreign firms to undercut domestic firms' offer by 6 to 12 percent to be awarded contracts. 1

To promote foreign purchases, the EU urges governments to publish all calls for tender above a certain minimum size at a European wide level. While this has increased the calls for tender published in the Official Journal of the European Communities from 12000 in 1987 to 90000 in 1995, the European Commission (1996a) still finds the proportion of imports in governments' purchases to be disappointingly low. In 1994, only 3\% of public procurement purchases were sourced directly from partner countries' markets (European Commission 1996b, p. 24). Additional measures for limiting local preferences seem to be required.

To answer the question of how to limit governments' local preferences in procurement we must understand what governments' motives are. Many studies interpret government preferences for local firms as a non-tariff trade barrier [cf., e.g., Herander (1982)]. Turnovsky (1988) shows how governments can use their procurement policies to mimic an optimal tariff. The problem with this explanation is that the introduction of tariffs is usually welfare decreasing, at least for small jurisdictions. The present paper develops an alternative model in which even small jurisdictions prefer a domestic firm to foreign firms even though the domestic firm charges a higher price for identical quality. The reason for this inefficient

\footnotetext{
${ }^{1}$ McAfee and McMillan (1989) pointed out that a preference for domestic firms may reduce the rent accruing to foreign bidders in procurement offers. For an auction theoretic analysis of the 'Buy American Act' see also Kim
} 
outcome is a fiscal externality among governments. If the jurisdictions within a federation decide to tax mobile factors, then public procurement in capital intensive sectors can redistribute tax revenues between jurisdictions. More precisely, awarding public procurement contracts in capital intensive sectors to less efficient domestic firms boosts that sector and attracts mobile capital. If capital is taxed one jurisdiction's tax revenue is increased at other

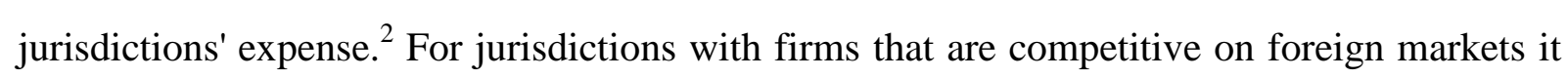
is somewhat more difficult to boost the domestic procurement sector since domestic purchases may simply crowed out exports. The model shows that, while these jurisdictions have no home bias, they may nevertheless buy too much of the procurement good to attract capital.

\section{$2 \quad$ A simple framework}

The emphasis of this paper is on the relation between procurement purchases and factor movements in a world with differently productive firms. The intention to study the connection between procurement, industry structure and factor movements suggests a Heckscher-Ohlin type of model, while the existence of differently efficient firms requires a Ricardo-type cost advantage. I assume that in each small jurisdiction (indexed $i$ ) there are three goods which may be produced: a tradable good, $T$, which is bought by governments only (tanks), a second tradable good, $F$, which is privately purchased (food), and a non-tradable, $N$. Production functions for $F$ and $N$ are identical across jurisdictions. Production functions for tanks differ across countries. Production requires capital $(K)$ and labor $(L)$. Labor is mobile between sectors but immobile between jurisdictions. Hence, in any jurisdiction $i$, total domestic labor,

(1994). Governments' higher concern for domestic firms' profits as opposed to those of foreign firms is also analyzed in Vagstad (1995).

${ }^{2}$ It has been frequently emphasized that countries should try to restrict the net capital outflow if capital is taxed. See MacDougall (1960), Kemp (1962, p. 62), Richman (1963), Musgrave (1969) and Alworth (1988, p. 233). This paper lays out how such a policy can be achieved with the instrument of government expenditures. A different way of attracting mobile capital has been identified in the case where governments supply public goods that increase capital productivity. See Fuest (1995). 
$\bar{L}_{i}$, can be allocated either to the tank, the non-tradable, or to the food industry. Capital is perfectly mobile between jurisdictions and between sectors. Production is of the CobbDouglas type. The following relationship is assumed to hold.

ASSUMPTION 1: The partial production elasticity of capital is highest in the production of tanks and is identical in sectors $N$ and $F$.

This leads to the following production functions

$$
\begin{gathered}
F_{i}=K_{F, i}^{\gamma} L_{F, i}^{1-\gamma} \\
T_{i}=a_{i} K_{T, i}^{\alpha} L_{T, i}^{1-\alpha} \\
N_{i}=K_{N, i}^{\gamma} L_{N, i}^{1-\gamma},
\end{gathered}
$$

where $a_{i}$ is a productivity parameter in tank production which differs among jurisdictions, while the partial production elasticities are identical across jurisdictions and are all smaller than one. ${ }^{3}$

Assumption 1 reflects the general perception that procurement intensive industries tend to be capital intensive. ${ }^{-1}$ The equality of partial production elasticities in the $N$ and $F$ sectors is for analytical convenience.

The representative consumer in jurisdiction $i$ receives utility from consuming food, $F_{C, i}$, and tanks, $T_{C, i}$, and the nontradable, $N_{C, i}$ :

\footnotetext{
${ }^{3}$ All the main results of the paper continue to hold if only labor productivity differed across possible tank producers, i.e., if $T_{i}=K_{T, i}^{\alpha}\left(a_{i} L_{T, i}\right)^{1-\alpha}$.

${ }^{4}$ For example, the capital intensity of utilities in Germany is ten times the average of the capital intensity in manufacturing (Institut der deutschen Wirtschaft 1999, table 37).
} 


$$
U_{i}=U_{i}\left\{F_{C, i} ; T_{C, i} ; N_{C, i}\right\}
$$

To enforce positive consumption levels for all goods, I assume that Inada conditions hold: $\partial U / \partial j>0, \partial^{2} U / \partial j^{2}<0, \partial U(0) / \partial j=\infty ; j=F_{C, i}, T_{C, i}, N_{C, i}$.

By assumption, tanks have no spillover effects on other members of the union. Because of their public good character, tanks are purchased by governments only. If $F_{i}^{*}$ denotes net food imports and $T_{i}^{*}$ is net tank imports, then consumption of food and tanks (indexed by subscript $c$ ) is given by domestic production plus net imports:

$$
F_{C, i}=F_{i}\left(K_{F, i}, L_{F, i}\right)+F_{i}^{*} ; T_{C, i}=T_{i}\left(K_{T, i}, L_{T, i}\right)+T_{i}^{*} .
$$

Each government is assumed to levy a tax on capital returns generated in its jurisdiction at the rate $t$. The tax may be thought of as a source based corporation tax. The tax rate is considered to be exogenous and identical across jurisdictions. ${ }^{6}$ Since jurisdictions are small, it may be questioned whether a tax on mobile capital can survive. In the present context, the taxation of capital may result from constitutional considerations, which may prescribe similar taxation of labor and capital income, or it could stem from an inter-jurisdictional harmonization of tax policies. The model also fits the case where a federal level of government sets a uniform tax rate but tax revenues are (partly) handed down to the jurisdiction where the income is earned. Germany is a possible example. Note that in the EU too there is currently a strong movement which demands a harmonization of capital income taxes.

\footnotetext{
${ }^{5}$ The number of consumers is normalized to unity.

${ }^{6}$ The assumption of identical tax rates simplifies things because it ensures that the value of $t$ in the current account equation (5) below is independent of whether the jurisdiction is a net capital importer or exporter.

${ }^{7}$ As an initial step, the EU has legislated a code of honor which is to rule out the most obvious tax incentives for firms. Additional measures towards tax harmonization have been recently demanded by the French Minister of Economics and Finance and by the European Commission.
} 
A harmonization of income taxes is only sensible if a central institution limits regional subsidy policies which would directly counter-act the harmonized tax policies. The paper therefore assumes that there are no regional subsidies. Qualitatively, the main results of the paper could be derived if subsidies existed but centrally imposed restrictions on the level of those subsidies were binding.

The balance of payments requires that net import of goods equals the net of tax interest on net capital exports:

$$
F_{i}^{*}+\bar{P} T_{i}^{*}+(1-t) r\left(K_{F, i}+K_{T, i}+K_{N, i}-\bar{K}_{i}\right)=0
$$

$r$ denotes the interest rate measured in units of food 8 and $\bar{P}$ is the market price of tanks in units of food as it applies to trade between jurisdictions. To ensure that such a market price exists, I assume that there are some jurisdictions that are so inefficient in producing tanks that they actually import them. More precisely, I adopt

ASSUMPTION 2: ( $i$ ) Among jurisdictions, $a$ is continuously distributed on the support $[\tilde{a}, \hat{a}] ; \tilde{a}<\hat{a}$. (ii) Jurisdictions with $a=\tilde{a}$ are assumed to be so inefficient in producing tanks that they will always specialize on food and the non-tradable for all values of $\bar{P}$ and $r$.

Firms will invest up to the point where the marginal value product equals the gross interest rate. Since the price of food is normalized to unity, the capital-labor ratio in the food industry, $k_{F, i}$, is completely determined by the gross interest rate and the technological parameter $\gamma$. If food is produced within a jurisdiction, then

\footnotetext{
${ }^{8}$ Note that, while $r$ is exogenous to any single jurisdiction, it is endogenous to the federation as a whole.
} 


$$
k_{F, i} \equiv \frac{K_{F, i}}{L_{F, i}}=\left(\frac{r}{\gamma}\right)^{\frac{1}{\gamma-1}} .
$$

Since the output price in the food industry is normalized to unity, the zero profit condition for firms implies

$$
1=\frac{w_{F, i} L_{F, i}+r K_{F, i}}{F_{i}}
$$

where $w_{F}$ denotes the wage rate in that industry. Competition and linear homogeneity in production then implies that the domestic price of tanks in units of food equals

$$
p_{i}=\frac{w_{T, i} L_{T, i}+r K_{T, i}}{T_{i}} .
$$

Using (7) and the differentiation of (2) with respect to $K_{T, i}$, yields

$$
w_{T, i}=\frac{K_{T, i} r(1-\alpha)}{L_{T, i} \alpha}
$$

as the wage in the tank industry. Similarly, the wage rate in the food industry and in the nontradeable sector can be calculated as

$$
w_{F, i}=\frac{K_{F, i} r(1-\gamma)}{L_{F, i} \gamma}
$$

$$
w_{N, i}=\frac{r(1-\gamma) K_{N, i}}{\gamma L_{N, i}} .
$$

\footnotetext{
${ }^{9}$ This uses $r=p_{i} \cdot \partial T_{i} / \partial K_{T, i}$.
} 
For countries which produce food, tanks and the non-tradable, wages in a labor market equilibrium must be identical across the three sectors. From (8), (9) and (10) this gives:

$$
\frac{K_{T, i}(1-\alpha)}{L_{T, i} \alpha}=\frac{K_{F, i}(1-\gamma)}{L_{F, i} \gamma}=\frac{K_{N, i}(1-\gamma)}{L_{N, i} \gamma} .
$$

Together with equation (6), equation (11) shows that the capital-labor ratios in all industries $\left(k_{j, i} ; j=N, T, F\right)$ are uniquely determined by the interest rate and the parameters of the production functions. It turns out that, because of assumption 1, the production of tanks is indeed the most capital intensive one.

For a jurisdiction which is specialized in tank production and has no food industry, the capital labor ratio is also given, but depends on the world market price for tanks:

$$
k_{T, i}^{S}=\frac{K_{T, i}}{L_{T, i}}=\left(\frac{\alpha a_{i} \bar{P}}{r}\right)^{1 /(1-\alpha)} ; \frac{K_{N, i}}{L_{N, i}}=k_{T, i}^{S} \frac{\gamma(1-\alpha)}{(1-\gamma) \alpha} .
$$

Equation (12) shows that a higher price as well as a higher productivity parameter $a_{i}$ allows capital to earn the interest rate $r$ at a higher capital intensity. Since the interest rate $r$ and the price $\bar{P}$ is given for any small jurisdiction, this implies that the wages in a tank exporting jurisdiction are higher the higher its productivity parameter.

Finally, consider the price of the non-tradeable, $q_{i}$. Zero profits imply

$$
q_{i}=\frac{w_{N, i} L_{T, i}+r K_{N, i}}{N_{i}}
$$

Together with a labor market equilibrium, it then follows that the price of the non-tradable is given by

$$
q_{i}=1
$$


if the jurisdiction produces food and the non-tradable, and by

$$
q_{i}=\frac{r}{\gamma}\left\{\frac{\gamma(1-\alpha)}{(1-\gamma) \alpha}\left(\frac{\alpha a_{i} \bar{P}}{r}\right)^{\frac{1}{1-\alpha}}\right\}^{1-\gamma}
$$

if only tanks and the non-tradeable are produced. Note that, in both cases, for any jurisdiction $i$ the price of the non-tradeable is exogenously given.

If a jurisdiction is producing food and tanks, then from (2), (6), (7) and (9), a tank producing firm will have to charge a price of

$$
p_{i}=\frac{k_{F, i}^{\gamma}+r\left(k_{T, i}-k_{F, i}\right)}{a_{i} k_{T, i}^{\alpha}}
$$

to recover factor cost. With given values of $k_{T}, k_{F}, r, \gamma$, and $\alpha$ the price of $p_{i}$ as defined in 15, for jurisdictions with a low $a_{i}$ will exceed $\bar{P}$. For those jurisdictions, it is clear that the own government's domestic purchases, $T_{G, i}$, are the only possible demand for the domestic tank sector, i.e. $T_{i}=T_{G, i}$. For jurisdictions with a high $a_{i}$, according to (15), $p_{i}$ falls short of $\bar{P}$. In this case, the production of food and tanks cannot be an equilibrium as this would imply pure profits in the tank industry. In those jurisdictions the tank sector has an incentive to increase. This increases labor demand and wages up to the point at which the food sector disappears.

Note that the government's decision about whether to buy tanks at home or abroad cannot prevent the economy from specializing in either tanks or food. Therefore, for any given jurisdiction $i$, the price and wage level are given on world markets. 


\section{The procurement decision of a small jurisdiction}

We are now able to formulate the governments' choice problem. The aim of this exercise is to establish that taxation leads to a home bias in the procurement decisions of comparatively inefficient jurisdictions. More precisely, by buying at home rather than abroad, those countries experience an income gain which can overcompensate the additional cost of domestic tanks. Moreover, as will be seen, tank producing jurisdictions are tempted to overprovide. That is, individual's marginal willingness to pay for tanks falls short of the market price, $\bar{P}$.

Given that for any jurisdiction $i$, wages and prices are constant, the utility of the representative household can be written as a function of tank consumption, $T_{C, i}$, and the private income, $Q_{i}$, which can be spent on food and the non-tradeable:

$$
V_{i}=V_{i}\left(Q_{i}, T_{C, i}\right)
$$

In the following I assume that $V_{i}$ is separable in $Q_{i}$ and $T_{C, i} .10$ Tank consumption is the sum of the government's domestic and foreign purchases, $T_{C, i}=T_{G, i}+T_{G, i} *$, and private income is national income, $y_{i}$, minus the government's budget:

$$
Q_{i}=y_{i}-\pi_{i} T_{G, i}-\bar{P} T_{G, i} *
$$

$\pi_{i}$ equals $p_{i}$ as given in eq. 15 if jurisdiction $i$ is a food producer and $\pi_{i}=\bar{P}$ otherwise.

$V_{i}$ is assumed to be quasi-concave. By assumption governments do not resell. ${ }^{1}$ For jurisdiction $i$ 's government we then have the following maximization problem:

\footnotetext{
${ }^{10}$ This will somewhat simplify derivation of eq. (28) below.

${ }^{11}$ This precludes dumping by governments, i.e. resale below purchase price, which implied an implicit subsidy to the procurement industry.
} 


$$
\max _{T_{G, i}, T_{G, i}^{*}} V_{i} \text { s.t. } T_{G, i}, T_{G, i}^{*} \geq 0
$$

As first order conditions to this problem we have

$$
\begin{gathered}
\frac{\partial V_{i}}{\partial T_{G, i}}=\frac{\partial V_{i}}{\partial Q_{i}}\left[\frac{d y_{i}}{d T_{G, i}}-\pi_{i}\right]+\frac{\partial V_{i}}{\partial T_{C, i}}+\lambda=0 \\
\frac{\partial V_{i}}{\partial T_{G, i}^{*}}=\frac{\partial V_{i}}{\partial Q_{i}}\left[\frac{d y_{i}}{d T_{G, i}^{*}}-\bar{P}\right]+\frac{\partial V_{i}}{\partial T_{C, i}}+\lambda *=0 .
\end{gathered}
$$

The Kuhn-Tucker conditions are

$$
\begin{aligned}
& T_{G, i} \cdot \lambda=0 ; T_{G, i} \geq 0, \lambda \geq 0 \\
& T_{G, i}^{*} \cdot \lambda *=0 ; T_{G, i}^{*} \geq 0, \lambda * \geq 0 .
\end{aligned}
$$

Combining (18) and (19) yields

$$
\frac{\partial V_{i}}{\partial Q_{i}}\left[\frac{d y_{i}}{d T_{G, i}}-\frac{d y_{i}}{d T_{G, i}^{*}}+\bar{P}-\pi_{i}\right]=\lambda *-\lambda
$$

If for a jurisdiction $d y_{i} / d T_{G, i}-d y_{i} / d T_{G, i}^{*}$ is larger than its price disadvantage $\pi_{i}-\bar{P}>0$, then equation (21) and the Kuhn-Tucker show that this jurisdiction will buy domestically produced tanks even though the price of these tanks exceeds the world market price.

To further investigate the possibility of such an outcome, consider the components of a jurisdiction's social income which consists of labor income accruing to $\bar{L}_{i}$ workers, the net of tax return on domestically owned capital, and the tax revenue on domestically employed capital:

$$
y_{i}=\bar{L}_{i} w_{i}+(1-t) r \bar{K}_{i}+r t\left(K_{T, i}+K_{F, i}+K_{N, i}\right)
$$


Since factor proportions are fixed and production is linear-homogenous, the products have fixed factor contents per unit of outputs. From the production functions and the definitions of $k_{F}, k_{N}$ and $k_{T}$, the absolute factor requirements as a function of production can be expressed as

$$
\begin{gathered}
K_{T, i}=\frac{T_{i}}{a_{i}} \cdot k_{T, i}^{1-\alpha} ; K_{F, i}=F_{i} \cdot k_{F, i}^{1-\gamma} ; K_{N, i}=N_{i} \cdot k_{N, i}^{1-\gamma} ; \\
L_{T, i}=\frac{T_{i}}{a_{i}} \cdot k_{T, i}^{-\alpha} ; L_{F, i}=F_{i} \cdot k_{F, i}^{-\gamma} ; L_{N, i}=N_{i} \cdot k_{N, i}^{-\gamma}
\end{gathered} .
$$

To evaluate the impact of domestic tank purchases on domestic income it is necessary to distinguish between food producing jurisdictions on the one hand and those which export tanks and do not produce food on the other hand.

\section{The income of a food producer}

For a food producer, the wage rate is given by $(9$. Together with 23 this yields 12

$$
y_{i}^{f}=\bar{L}_{i} k_{F} \frac{r(1-\gamma)}{\gamma}+(1-t) r \bar{K}_{i}+r t\left\{\frac{T_{i}}{a_{i}} k_{T, i}^{-\alpha}\left(k_{T, i}-k_{F, i}\right)+\bar{L}_{i} k_{F, i}\right\} .
$$

Since for a food producer $p_{i}>\bar{P}$, the own government is the only potential purchaser of domestically produced tanks: $T_{i}=T_{G, i}$. Therefore from (24),

$$
\frac{d y_{i}^{f}}{d T_{G, i}}=\frac{d y_{i}^{f}}{d T_{i}}=\frac{r t}{a_{i}} k_{T, i}^{1-\alpha}\left(1-\frac{(1-\alpha)}{\alpha} \frac{\gamma}{(1-\gamma)}\right)
$$

which, after substitution, gives

$$
\frac{d y_{i}^{f}}{d T_{i}}=\frac{r t}{a_{i}}\left(\frac{r}{\gamma}\right)^{\frac{1-\alpha}{\gamma-1}}\left(\frac{(1-\gamma) \alpha}{\gamma(1-\alpha)}\right)^{1-\alpha}\left(1-\frac{(1-\alpha)}{\alpha} \frac{\gamma}{(1-\gamma)}\right)
$$


Since by assumption 1, $\alpha$ exceeds $\gamma$, the domestic income is an increasing function of domestic tank purchases.

Since tank exports are zero for $p_{i}>\bar{P}$, tank purchases abroad do not lead to a shift in domestic production between food and non-tradables on the one hand and tanks on the other hand. Since capital intensity therefore stays constant, $d y_{i}^{f} / d T_{i}^{*}=0$.

\section{The income of a non-food producer}

The income effect from additional tank purchases may also be distortive for a jurisdiction that is specialized in tanks and for which $\pi_{i}=\bar{P}$. For such a jurisdiction, the wage rate is given by (8) and (12). Domestic income then equals

$$
\begin{aligned}
& y_{i}^{t}=\left(\frac{\alpha a_{i} \bar{P}}{4^{r}{ }_{2}}\right)_{3}^{\frac{1}{1-\alpha}} \frac{r(1-\alpha)}{\alpha} \bar{L}_{i}+(1-t) r \bar{K}_{i}
\end{aligned}
$$

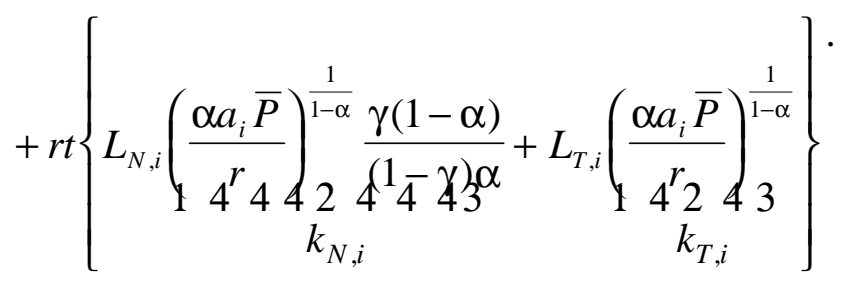

Substituting from 23 , using the labor market clearing condition and differentiating gives

$$
\frac{d y_{i}^{t}}{d T_{i}}=t \alpha \bar{P}\left(1-\frac{(1-\alpha)}{\alpha} \frac{\gamma}{(1-\gamma)}\right)
$$

which again is positive. Unlike $d y_{i}^{f} / d T_{i}, d y_{i}^{t} / d T_{i}$ is independent of the productivity parameter $a_{i}$. The reason is that, for the non-food producer, an increase in $a_{i}$ keeps the difference between the capital intensities of the non-tradable and of tanks constant. A marginal

\footnotetext{
${ }^{12}$ See the appendix.
} 
increase in domestic tank output has therefore the same effect on capital inflows for all jurisdictions independent of the value of $a_{i}$.

Unlike with food producers, the number of tanks produced does not match the number of tanks bought domestically. Instead, domestic production is given by the government's domestic purchases plus (net) exports. Exports in turn are determined by the current account equation (5). Therefore consumer reaction to increased government purchases is crucial for evaluating how total tank production can be influenced by government policy. From the separability of consumers' utility and from the fact that all prices are given to the jurisdiction, it follows that consumption of food is only a function of private income, $Q_{i}$.

Implicit differentiation of the balance of payment identity then gives:

$$
\frac{d T_{i}}{d T_{G, i}}=\frac{d T_{i}}{d T_{G, i}^{*}}=\frac{1-\partial F_{C, i} / \partial Q_{i}-\left(\partial K_{N, i} / \partial N_{C, i}\right)\left(\partial N_{C, i} / \partial Q_{i}\right)(1-t) r}{1-\frac{1}{\bar{P}} \frac{\partial F_{C, i}}{\partial Q_{i}} \frac{d y_{i}}{d T_{i}}-\frac{(1-t) r}{\bar{P}}\left(\frac{\partial K_{T, i}}{\partial T_{i}}+\frac{\partial K_{N, i}}{\partial N_{i}} \frac{\partial N_{C, i}}{\partial Q_{i}} \frac{d y_{i}}{d T_{i}}\right)}
$$

From the private consumer's budget constraint, $\left(1-\partial F_{C, i} / \partial Q_{i}\right) / q_{i}=\partial N_{C, i} / \partial Q_{i}$. Therefore, in the border case of $\partial F_{C, i} / \partial Q_{i}=1, d T_{i} / d T_{G, i}=0$. However, since both $N$ and $F$ can be interpreted as broad bundles of goods, it is reasonable to make

Assumption 3: $0<\partial F_{C, i} / \partial Q_{i}<1$.

Inserting into (28) from (14) and (27) yields

\footnotetext{
${ }^{13}$ This is different in the case of food producers. For these, the capital intensity in food production is given by the interest rate and the world market price of output. The lower $a_{i}$ for a food producer, however, the higher the capital intensity must be to earn the wage rate offered in the food industry. This implies that the capital inflow from a marginal increase in tank production is higher the lower is $a_{i}$.
} 


$$
\frac{d T_{i}}{d T_{G, i}}=\frac{1-\partial F_{C, i} / \partial Q_{i}-\left(1-\partial F_{C, i} / \partial Q_{i}\right) \gamma(1-t)}{1-\frac{\partial F_{C, i}}{\partial Q_{i}} t \alpha\left(1-\frac{(1-\alpha) \gamma}{(1-\gamma) \alpha}\right)-(1-t) \alpha-(1-t)\left(1-\frac{\partial F_{C, i}}{\partial Q_{i}}\right) \gamma t \alpha\left(1-\frac{(1-\alpha) \gamma}{(1-\gamma) \alpha}\right)}
$$

$$
=\frac{(1-\gamma)\left(1-\partial F_{C, i} / \partial Q_{i}\right)}{(\alpha-\gamma) t\left(1-\partial F_{C, i} / \partial Q_{i}\right)+1-\alpha}>0
$$

which is always positive under assumption 3. The intuition is as follows. An expansion of domestic government purchases by one dollar leads to an initial reduction of private net of tax income by one dollar. If the reduction in net income only reduced the demand for tradables, then the balance of payments identity would require tank exports to fall by the same extent, namely one dollar, and total tank production would stay constant. If, however, some of the loss in available private income reduces demand for non-tradables (as assumption 2 implies), then food imports and tank exports fall by less than one dollar. Tank production increases, leading to an inflow of capital and an increased domestic income.

\section{The social cost of domestically produced tanks}

From the perspective of a single jurisdiction, the social cost of producing a marginal tank, defined as the factor cost net of additional tax revenues for the jurisdiction, falls short of the factor cost $p_{i}$ as perceived by a local firm. ${ }^{14}$ Given that capital is taxed, the additional tax revenue from inflowing capital reduces the social cost. For a food producer, the social cost can be written as

$$
C^{f}=\frac{1}{a_{i}}\left\{\left[\frac{k_{F}^{\gamma}-r k_{F}+r k_{F} \frac{(1-\gamma) \alpha}{\gamma(1-\alpha)}}{\left(k_{F} \frac{(1-\gamma) \alpha}{\gamma(1-\alpha)}\right)^{\alpha}}\right]-r t\left[\left(k_{F} \frac{(1-\gamma) \alpha}{\gamma(1-\alpha)}\right)^{1-\alpha}\left(1-\frac{(1-\alpha) \gamma}{\alpha(1-\gamma)}\right)\right]\right\}
$$


Given that the social cost is positive, which is a necessary condition to fulfill (19, 30, shows that, for a food producer, $C^{f}$ is a decreasing function of $a_{i}$.

For a jurisdiction which is specialized in tanks, from $(27)$ and the exogeneity of $\bar{P}$, the social cost $C^{t}=\bar{P}-d y_{i} / d T_{i}$ is independent of $a_{i}$. Unlike in the case of the food producer, however, the social cost of producing another tank and the social cost of buying another tank are not the same. This comes from the fact that, for a tank exporter, domestic purchases are not identical to domestic production. The social cost of buying another tank falls short of (exceeds) the social cost of producing another tank if $d T_{i} / d T_{G, i}$ as given by 29 falls short (exceeds) unity. Theoretically, both cases are conceivable.

Figure 1: Comparative advantage and production

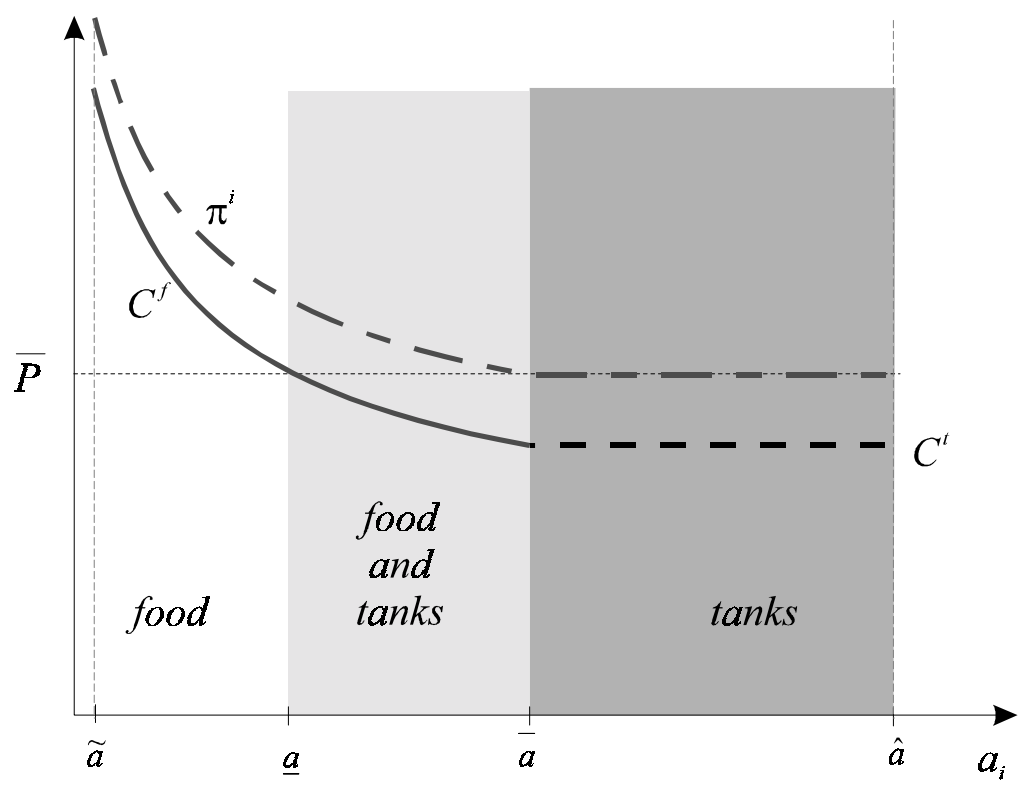

Figure 1 illustrates the production pattern which emerges. From assumption 2(ii), the least productive jurisdictions will not find it profitable to produce tanks. As $a_{i}$ increases, $C^{f}$

\footnotetext{
${ }^{14}$ Social cost in the following refers to the cost to the local jurisdiction and not to the social cost of the federation as a whole.
} 
continuously decreases and is always below $\pi_{i}$. Let $\bar{a}$ be the lowest value of $a$ at which jurisdictions are competitive at the market and still specialize on tank production. Then from the continuity of $C^{f}$ and the continuous distribution of $a_{i}$ (assumption $2(i)$ ) it follows, that there is a range of jurisdictions, $[\underline{a}, \bar{a}[$, which produce tanks but for which production cost exceed the market price: $\pi_{i}>\bar{P}$. The fiscal externality induces local governments' to buy their tanks domestically and the jurisdictions produce tanks and food. Starting from a certain level $\bar{a}$, jurisdictions are tank exporters and import food.

As mentioned at the start of section 3, a possible distortion is not only that some jurisdictions face an home bias, but also that tank producers excessively purchase this procurement good. Therefore, consider the amount of tanks purchased by tank producing jurisdictions. For competitive jurisdictions we have $p_{i}=\bar{P}$. With the help of eqs. 21 and (28) it can be shown that for these $\lambda=\lambda *$ holds. Since the Inada conditions of the utility function imply that some tanks are always purchased, i.e. $\lambda, \lambda^{*}>0$ is not a solution, it must hold that $\lambda=0$. From eq. 18 it then follows that for all competitive jurisdictions, the marginal rate of substitution falls short of the market price $\bar{P}$. The same holds for noncompetitive firms which nevertheless buy at home as for these $\lambda=0$ holds directly from (21).

Note however, that the fact that the marginal rate of substitution falls short of the market price does not automatically imply that more tanks are purchased than under a situation where the tax externality of tank production is absent. One reason is that the production by relatively inefficient jurisdictions reduces overall income in the federation. A second reason is that, for the federation as whole, $r$ is endogenous. A higher demand for capital intensive goods drives up $r$ and increases the relative price of tanks compared to less capital-intensive goods. 


\section{$4 \quad$ Remedies}

The preceding analysis showed that taxation of mobile capital can induce inefficient jurisdictions to produce the capital intensive procurement good. This is the first distortion that has been identified. A second distortion arises since for tank producing jurisdictions, the marginal willingness to pay falls short of the market price of tanks.

One possible strategy for correcting both distortions is to abolish harmonized taxation. The hope could be that tax competition between small jurisdictions would lead to a vanishing capital income tax and the above mechanism would disappear. Of course, proponents of tax coordination would object that this may seriously harm member jurisdictions' ability to finance public goods and to redistribute.

Another idea would be to tax domestic purchases to correct for the home bias of inefficient jurisdiction. In the optimum, the tax would be just as high to rule out that nonexporting countries are producing tanks and for these countries, both distortions could be corrected. Such a tax, however, must take into account the fact that the home bias in procurement was established only for jurisdictions that are comparatively inefficient in producing the procurement good. Efficient jurisdictions that are competitive on the market must therefore be exempted from that tax. However, to eliminate the second distortion, a tax on all purchases (imports and domestic purchases) of efficient jurisdictions at a different rate is conceivable. Since for efficient jurisdictions the income effect works only indirectly via the current account restriction, the appropriate tax rate will be extremely hard to evaluate. Taken together, Pigouvian taxation does not seem to be a very practicable way to proceed.

Perhaps a more conceivably remedy would be to share tax receipts among jurisdictions, for example, by introducing some kind of a fiscal equalization scheme. If additional tax revenues from a more capital intense production must shared with other member jurisdictions, incentives for beggar-your-neighbor policies through manipulation of 
capital inflows lose attractiveness. This proposal is in striking contradiction to the general evaluation of the German fiscal equalization scheme which has been frequently criticized for reducing local incentives for collecting taxes. The (implicit) assumption of those critics is that jurisdictions only undertake measures which increase tax revenues that are not at their partner jurisdictions' cost. Such measures may include growth promotion, deregulation, etc. In this paper, beggar-your-neighbor policies are the only way of influencing tax revenues. Reducing those incentives is clearly beneficial. In the real world, both types of revenue promotion should be possible and more research about a possible trade-off between socialization of tax revenues and full retention of local revenues should be in demand.

\section{$5 \quad$ Final remarks}

The message of the paper is that in federations with harmonized capital taxation the home bias in procurement decisions can potentially be explained by a fiscal externality. This has been shown to hold for jurisdictions which cannot compete in outside markets. The intuition for the result is that procurement decisions have an impact on industry structure. Industry structure in turn influences the location of taxable factors of production and may change the distribution of tax revenues between jurisdictions.

There clearly is scope for future research. The analysis assumed perfect labor markets and full employment. The exact government incentives in the case of unemployment certainly require a more detailed analysis which, among other things, should explicitly model the reason for the unemployment.

Finally, a more complete analysis should also consider the outside world. If capital is perfectly mobile not only within the federation but also with respect to the rest of the world, then, from a federal view, one could be less critical about member jurisdictions' efforts to attract capital as the fiscal externality partly falls on the outside world. 


\section{Bibliography}

Alworth, J.S. (1988), The finance, investment and taxation decisions of multinationals. Oxford: Basil,.

European Commission (1993), The Economics of Community Public Finance. European Economy: Reports and Studies No.5.

European Commission (1996a), Com(96) 520.

European Commission (1996b), "Economic evaluation of the internal market", European Economy: Reports and Studies, 4/1996.

Fuest, C. (1995), "Interjurisdictional competition and public expenditure: Is tax co-ordination counterproductive", Finanzarchiv 52, 478-496.

Herander, M. (1982), "The impact of government price discrimination and its equivalence with the tariff", Weltwirtschaftliches Archiv 118, 525-545.

Institut der deutschen Wirtschaft (1999), Zahlen zur wirtschaftlichen Entwicklung der Bundesrepublik Deutschland. Cologne: Deutscher Instituts-Verlag.

Kemp, M.C. (1962), "Foreign investment and national advantage", Economic Record 38, 5662.

Kim, I.-G. (1994), "Price -preference vs. tariff policies in government procurement auctions", Economic Letters 45, 217-222.

MacDougall, G.D. (1960), "The benefits and costs of private investments from abroad: A theoretical approach", Economic Record 36, 13-35.

McAfee, P. and McMillan, J. (1989), "Government procurement and international trade", Journal of International Economics 26, 291-308.

Musgrave, P.B., (1969), United States taxation of foreign investment income: Issues and arguments. Cambridge (MA): International Tax Programm, Harvard Law School.

Oates, W. (1972), Fiscal federalism. New York: Harcourt.

Richman, P.B. (1963), Taxation of foreign investment income. Baltimore: Johns Hopkins Press.

Turnovsky, S.J. (1988), "The gains from fiscal cooperation in the two-commodity real trade model", Journal of International Economics 25, 111-125.

Vagstad, S. (1995), "Promoting fair competition in public procurement", Journal of Public Economics 58, 283-307.

\section{Appendix}

\section{The income of the food producer}

The capital requirement for the production of $N$ and $F$ can be calculated from the residual employment:

$$
L_{F, i}+L_{N, i}=\bar{L}_{i}-L_{T, i}=\bar{L}_{i}-\frac{T_{i}}{a_{i}} k_{T, i}^{-\alpha}
$$


From the definition of the capital intensity and from $k_{F, i}=k_{N, i}$,

$$
K_{F, i}+K_{N, i}=\left(\bar{L}_{i}-\frac{T_{i}}{a_{i}} k_{T, i}^{-\alpha}\right) \cdot k_{F, i}
$$

Using this in 22 gives (24). 